IN BRIEF

- The remand prison population represents $18 \%$ of the total prison population in the UK.

- Remand prisoners have compromised general and oral health compared with the general non-prison population.

- Remand prisoners exhibit high levels of mental illness and infectious disease.

- Poor oral health presented with high levels of decay and low levels restorative treatment.

- Non-healthy behaviours such as recreational drug use, tobacco smoking, alcohol consumption, and diets high in sugar content were commonplace.

\title{
Oral health of Brixton remand prisoners
}

\author{
Oral health of remand prisoners in HMP Brixton, London E. Heidari, ${ }^{1}$ C. Dickinson, ${ }^{2}$ R. Wilson ${ }^{3}$ and J. Fiske ${ }^{4}$
}

\section{ABSTRACT}

\section{Overview}

This study investigated the general and oral health status and behaviours and the dental treatment requirements of remand prisoners. It makes recommendations on how their oral health care needs may be met.

\section{Method}

A convenience sample of 78 remand prisoners participated in the study within HMP Brixton. The study involved a structured interview, to establish health status and behaviours as well as perceived oral health needs, combined with an oral examination to establish normative treatment need.

\section{Results}

Prisoners' general health was compromised. In particular, there were high levels of mental illness and infectious disease. Unhealthy behaviours such as tobacco smoking, alcohol use, drug dependency, and high sugar diets were commonplace. This affected the remand prisoners' oral health, which presented with high levels of decay and relatively low levels of both missing and filled teeth. Whilst prisoners made high use of prison dental services, they made little use of dental services outside of prison. The high turnover of remand prisoners and high demand for emergency care made the delivery of preventive and routine care difficult.

\section{Conclusion}

Remand prisoners have compromised general and oral health compared with the general population. They exhibit poor oral health, which is contributed to by their lifestyles and health behaviours.

\section{EDITOR'S SUMMARY}

As well as providing an interesting overview of the oral health of remand prisoners, this study also gives a fascinating insight into the general health, habits and behaviours of this group of people. The demographic profile paints a picture of individuals who are disadvantaged in many respects and who in other studies or surveys may be categorised as non-regular attenders, without further definition. However, the additional information here is useful not only as a baseline for future planning of dental care within the prison service but also as a marker for practitioners who may see and treat such patients once they have been released.

Additionally the paper serves to illustrate the mixture we face in dentistry between the purely scientific, or clinical side of our work and the social or human aspects. If the paper had surveyed a 'population' of people with such poor oral and general health without specifying who and where they were, I wonder if our reaction would be the same as it is to knowing that they are prisoners? Of course, it should not affect the quality of care that we would provide but should their social situation and attitudes to health behaviour affect our treatment planning for them?

The use of alcohol and tobacco would place many of the studied individuals at greater risk of the development oral cancer, their diets and oral hygiene habits also suggest that the chances of retaining many teeth into older age would be substantially reduced. So how do we approach the treatment, or more pertinently prevention, of disease for such patients in order to increase their chances of rehabilitation into society and restoration of self respect and reasonable health? Although the authors state that there are few published studies on the oral health of prisoners, I suspect that we may well see greater attention to this section of society in the future.

The full paper can be accessed from the $B D J$ website (www.bdj.co.uk), under 'Research' in the table of contents for Volume 202 issue 2.

Stephen Hancocks OBE, Editor-in-Chief

Editor-in-Chief


TO ACCESS THE BDJ WEBSITE TO READ THE FULL PAPER:

- BDA members should go to www.bda.org

- Do not login on the BDA home page, if you are already logged in, please log out.

- Then, in www.bda.org click on the link to the BDJ in the top left of the screen. A new window will open. If a new window fails to open please check the settings of any pop up blocker software that you have installed on your computer.

- You will now be asked to login with your BDA website login details which are on your BDA membership card.

- Once your details have been entered you will be transferred to the BDJ website. If your login does not work please contact the BDA Membership Department on 02075634555.

- If you are not able to access the article on the BDJ website there may be an issue with your system's firewall. If so, return to the BDA homepage and click on the link 'BDJ access problems' and follow the step by step guide.

\section{AUTHOR QUESTIONS AND ANSWERS}

\section{Why did you undertake the research?}

There are limited numbers of published studies related to the oral health of prisoners in the UK, but those that exist in both the UK and USA report that prisoners have poorer oral health than the general population. This matched the first author's subjective view based upon experiences at a young offenders' institute and a local male prison in London. Discussions with prisoners in the prison dental surgery led to an interest in the prison population's perspective of oral health. Prisoners appeared to justify continuous unhealthy 'behaviours' due to the high stress imposed on them in the prison establishment. We were interested in the attitudes towards oral health in relation to the normative need and wondered if there were differences between different prison populations, such as remand and convicted prisoners. This led to trying to understand more about prisoners' knowledge and views of oral health, past use of dental services, dental treatment experience, as well as their current oral health status.

\section{What would you like to do next with your research?}

We hope that the results will contribute to an understanding of the wider picture of factors that affect prisoners' oral health. In turn, we hope that this understanding can be used to improve the oral health care and dental service provision for prisoners, both locally and beyond. We would hope that the authorities (health or prison) could commission a larger study of prisoners' dental needs to look at the national versus local oral health need of prisoners. This would allow truly targeted commissioning of dental services, dependent on need.

There is also scope for investigation of other variables with a wider study, such as the skill base and mix required to treat this 'at risk' population. It seems apparent that this population has the need for dental care professionals with knowledge, training, experience and skills in special care dentistry. Also, what would be the role for dental care professionals such as hygienists, therapists and oral health promoters?

On the national level it would seem appropriate to develop a standard oral health needs assessment (possibly in collaboration with the Prison Health Research Network) to enable identification and comparison of needs within and between different type of prisoners and establishments. This could be linked to a study of 'discharge oral health status.' This would allow assessment of the effectiveness of prison oral health service during prison stay.

Further studies are needed to improve awareness of oral health status in different prison populations in the UK, at a national and local level. Studies should be linked to any local and national strategies for oral health service provision.

\section{FULL PAPER DETAILS}

${ }^{1 *}$ Senior Dental Officer, ${ }^{2}$ Associate Specialist in Special Care Dentistry, ${ }^{3}$ Senior lecturer in Oral Science, ${ }^{4}$ Senior Lecturer/Consultant in Special Care Dentistry, King's College London Dental Institute at Guy's, King's and St Thomas' Hospitals, Guy's Tower, Guy's Hospital, London, SE1 9RT

${ }^{*}$ Correspondence to: Dr Ellie Heidari

Email:ellie.heidari@kingsch.nhs.uk

Refereed Paper

Accepted 8 March 2006

DOI: $10.1038 /$ sj.bdj.2007.32

British Dental Journal 2007; 202: E5

\section{COMMENT}

Remand prisoners comprise $18 \%$ of the total prison population in the UK, and only half of these go on to serve custodial sentences. This paper presents empirical evidence and methodological discussion of research on the oral health of this distinct subset, whose circumstances cannot be assumed to be the same as those of the general prison population.

The health behaviours of the sample are distinctive: $78 \%$ were smokers, $83 \%$ used illicit drugs, and they had both high normative and perceived needs for dental treatment. Fifty-four percent of the sample's most recent visit to the dentist was in prison and due to reduced barriers to access, the population use prison dental services more than on the 'outside'. Consequently longer stay convicted prisoners have better oral health than the remand prison population. Furthermore, HMP Brixton's whole team approach to health benefits convicted prisoners more than remand prisoners, again underlining the importance of considering this part of the prison population discretely.

In addition to the empirical contribution of this research, this paper also offers an engaging account of the methodological challenges in undertaking the work. Facing problematic recruitment for more conventional methods, the research utilises a convenience sample of 78 remand prisoners participating in structured interviews to address literacy problems written surveys would encounter. Participants were offered treatment in return for participation, raising issues of reciprocity as an ethical dimension of research.

The authors recommend that addressing the oral health of remand prisoners requires integrating dental screening into on-arrival medical checks, introducing oral health education programmes and integrating dental records into the new centralised electronic systems to help continuity of care. In a climate of stretched resources, it may be difficult to see this population as important, but clearly health care providers have a responsibility to marginalised groups with demonstrably compromised health, and with the remand prison population rising 6\% ${ }^{1}$ between May 2005 and May 2006, this research identifies the issues relating to a growing service need.

K. Stewart, Lecturer in Medical Sociology, Cardiff University School of Dentistry

1. National Offender Management Service. Population in custody monthly tables: May 2006 England and Wales. Home Office, http://www.homeoffice. gov.uk/rds/pdfs06/prismay06.pdf. Accessed 11 July 2006. 